\title{
A LAICIDADE NO BRASIL E A TEOLOGIA PÚBLICA
}

\section{The Secularism in Brazil and the Public Theology}

\author{
Michele Janene Karigyo ${ }^{1}$ \\ Alonso Gonçalves ${ }^{2}$ \\ Paula de Magalhães Corrêa Campos ${ }^{3}$ \\ Ilo Rodrigo de Farias Machado ${ }^{4}$
}

\section{RESUMO}

O Brasil se formata como um Estado que apesar do advento da secularização, não deixou as questões referentes à religião distantes do ambiente público. Ao contrário, o Brasil possui uma laicidade singular, de modo que as linguagens da fé estão presentes no espaço público e institucional, o que pode conduzir para o diálogo entre a diversidade de vozes que operam na sociedade. É nesse ambiente plural e laico, com vistas a um diálogo proveitoso e enriquecedor para a vida, que a Teologia Pública se constitui no território brasileiro, buscando construir pontes que propiciem de modo intencional, pedagógico e autêntico, a construção de uma convivência respeitosa na diversidade.

Palavras-chave: Laicidade; Teologia Pública; pluralidade.

\begin{abstract}
Brazil is formatted as a State that, despite the advent of secularization, has not left issues relating to religion far from the public sphere. On the contrary, Brazil has a singular secularity, so that the languages of faith are present in the public and institutional space, which can lead to a dialogue between the diversity of voices that operate in society. It is in this plural and secular environment, with a view to a fruitful and enriching dialogue for life, that Public Theology is constituted in the Brazilian territory, seeking to build bridges that intentionally, pedagogically and authentically provide the construction of a respectful coexistence in diversity.
\end{abstract}

Keywords: Secularism; public theology; pluralism.

\footnotetext{
${ }^{1}$ Mestranda do Programa de Pós-graduação em Teologia pela Faculdade Teológica Sul Americana. Graduada em Teologia pela Faculdade Teológica Sul Americana. Graduada em Direito pela Universidade Norte do Paraná. Advogada (OAB/PR 54.263).

${ }^{2}$ Doutor em Ciências da Religião (Universidade Metodista de São Paulo). Pós-doutor em Teologia (Pontifícia Universidade Católica de São Paulo). Licenciatura em Filosofia (Instituto de Ciências Sociais e Humanas). Graduado em Teologia (Faculdade de Ensino Teológico de São Paulo). Docente no Programa de Pós-graduação em Teologia da Faculdade Teológica Sul Americana (Londrina/PR).

${ }^{3}$ Mestranda do Programa de Pós-graduação em Teologia pela Faculdade Teológica Sul Americana. Graduada em Pedagogia pela Universidade Federal Fluminense. Professora e Pedagoga da Fundação Pública Municipal de Educação de Niterói.

${ }^{4}$ Mestrando do Programa de Pós-graduação em Teologia pela Faculdade Teológica Sul Americana. Graduado em Teologia pela Faculdade Teológica Sul Americana. Graduado em Direito pelo Centro Universitário da Grande Dourados. Procurador do Município de Dourados.
}

REVISTARELEGENS THRÉSKEIA - 2021 - UFPR 


\section{Introdução}

A secularização produziu efeitos mitigados no território brasileiro. A presença da religião, de seus valores, de seu modo de ver o mundo, mantiveram-se vivas. O Espaço Público brasileiro não se libertou de fé. A cruz pendurada nas paredes dos diversos auditórios pertencentes aos Poderes Constituídos, a Lavagem do Bomfim, a cruzada para Aparecida do Norte, a aulas confessionais, os templos fechados na pandemia, são exemplos de que, no Brasil, o religioso, o sagrado, estão de modo constante e multifacetado no espaço público e institucional.

Mediante pesquisa bibliográfica, este artigo busca analisar uma aproximação sobre como pensar a Teologia Pública no Brasil, destacando a realidade brasileira que, por apresentar uma laicidade peculiar, circunscreve a religião no espaço público de formas, por vezes, contraditórias. Neste ambiente, argumentamos a necessidade da produção de uma Teologia Pública que se apresente como uma voz autêntica e respeitosa, que promova, antes de um discurso, um diálogo para se fazer conhecida e conhecer a realidade.

A nossa proposta, mais do que colocar uma formatação conceitual que estanque a ideia do que seria Teologia Pública, é a de pensar a necessidade de uma Teologia Pública que seja contextual e que respeite a Laicidade do Estado, tendo como perguntas norteadoras: qual seria o papel da Teologia Pública no Brasil? Seria possível uma função dialogal transformada em práxis?

\section{A Laicidade brasileira}

A laicidade do Estado brasileiro ocasionou uma secularização da sociedade até certo ponto. A liberdade religiosa garantida por lei abriu espaço para o convívio entre inúmeras expressões religiosas na vida pública, de forma que as novas religiões concorressem entre si e exigissem os mesmos direitos que o catolicismo sustentou mesmo com a separação Estado/Igreja. Montero (2009) indica que mesmo a modernidade não foi suficiente para que houvesse declínio da religião, pelo contrário, o Estado Democrático impulsionou a criação de novos movimentos religiosos e ampliou a noção de campo religioso para novas dimensões da vida social, e que ao invés de privatizarem-se de vez, entrepuseram-se das mais variadas formas na construção e na gestão do espaço público. 
A presença religiosa se manifesta de diversas maneiras no espaço público (MONTERO, 2009). No campo da linguagem, por exemplo, a religião ressignifica o que entendemos por igualdade de direitos, introduz no debate político os valores religiosos e mobiliza grupos sociais em torno de determinada causa. Nesse sentido, ela opera uma noção de cidadania que dá lugar a lutas por direitos pontuais, pautados por valores próprios que ao ganharem proporções maiores no debate público, restringem o direito à cidadania em seus aspectos mais amplos e fundamentais para a vida.

Oro (2005) avança nessa reflexão quanto à presença religiosa, mostrando que no quadro atual brasileiro, ocorrem fatos novos na relação entre religião e política, sempre imbricados com momentos históricos e políticos fomentados pela intolerância e pela polarização, nos levando a ponderar até que ponto a participação da religião no espaço público, e até mesmo na política, é algo concebível numa democracia.

Por esses motivos, para analisar laicidade no Brasil é preciso encontrar um conceito capaz de identificar um ponto de convergência, entre as várias vozes religiosas que ocupam o espaço público brasileiro frente ao fenômeno europeu que implode a separação entre a religião e o Estado. Logo, para o conceito de laicidade no território brasileiro é importante questionar as análises sociológicas realizadas sobre o papel da secularização neste lado do planeta.

Uma das críticas mais contundentes que se faz à teoria da secularização consiste em questionar a avaliação que as análises sociológicas fazem do lugar e do papel da religião na modernidade. Nesse sentido, boa parte das críticas recai sobre noções da secularização que operam com uma linguagem teleológica e a-histórica da teoria da modernização e que, dessa forma, tendem a padecer de sérias dificuldades (quando se dispõem a fazê-lo) para explicar a variabilidade e a contingência histórica dos processos de secularização. (GORSKI; ALTINORDU, 2008, p. 59) (MARIANO, 2011. p. 239).

Nesse caminho de busca conceitual acerca da laicidade brasileira, interessante análise se observa em Camurça (2017), que, de maneira antropológica, destaca que a análise da laicidade no Brasil perpassa não apenas o conhecimento jurídico-normativo, mas também, é necessário conhecê-la em uma abrangência maior, ou seja, é preciso aprender o fenômeno sob outros pontos de vistas, ponto esse que veio a chamar "de ponto de vista nativo":

Ao invés do que a laicidade deve ser segundo paradigmas jurídicos, constitucionais e programáticos, deve-se contemplar como os atores sociais contextualizados se apropriam destas normas consagradas como "regime laico" em função dos seus interesses e projetos. (CAMURÇA, 2017, p. 859). 
Camurça (2017) apresenta quatro cenários que expressariam espaços em que diversos "atores sociais (laicos e religiosos) investem discursos, dispositivos legais, midiáticos, políticos para estabelecer uma configuração do que compreendem como o lugar do religioso no espaço público, ou do que seja um regime de laicidade". O primeiro cenário, o das ações religiosas no campo da moral, refere-se à investida de evangélicos contra "iniciativas protagonizadas por setores laicos no cenário jurídico- político que buscavam expandir uma agenda em torno de direitos humanos e cidadania”. (CAMURÇA, 2017, p. 863).

No segundo, conforme Camurça (2017), além de crucifixos, a utilização da bíblia em espaços públicos parece ter sido encampada por movimentos católico-evangélicos que nutrem a ideia de que valores espirituais devem servir como reserva moral da nação.

No terceiro, de contenção religiosa no espaço público, observa-se iniciativas judiciais para, através de uma interpretação constitucional, proceder uma análise sobre o laivo, por exemplo, a retirada dos crucifixos de recintos públicos, uma vez quer tal preceito fere a laicidade. Referidos pedidos não foram todos acolhidos. (CAMURÇA, 2017).

O fenômeno da laicidade tem no Brasil, características peculiares que demonstram o não perecimento da relação "Estado x Religião" como pressupunham os que defendiam o fim do cristianismo com a chegada da modernidade. Em que pese a força dos movimentos que propagavam o fenômeno da secularização pelo mundo, o Brasil manteve como religião oficial o catolicismo. Isso ocorreu durante todo o período colonial, bem como, durante o período imperial.

Não se pode esquecer que a figura do Padroado sempre esteve forte na estruturação do Brasil ainda enquanto colônia. O padroado conferia à Coroa o direito de redistribuir os dízimos devidos à Igreja e indicar os ocupantes de alguns cargos eclesiásticos. Assim, com esse mecanismo, considerando o poder concedido nos termos da bula Inter Caetera, que concedeu a administração espiritual das novas terras conquistadas a Ordem de Cristo, o Rei se tornava aquele que indicava os responsáveis pelas Paróquias das novas terras. Contudo, com a criação do Bispado de Funchal, após 1515, no Brasil não vigorou a Ordem de Cristo.

Segundo Hoornaert, o padroado constituiu a "expressão prática do colonialismo em termos de instituições religiosa"2, na medida em que conferia à Coroa o direito de arrecadar e redistribuir os dízimos devidos à Igreja e indicar os ocupantes de todos os cargos eclesiásticos, inclusive infra episcopais. Desde 1455, a bula Inter Caetera, de Calixto III, confirmara a administração espiritual da Ordem de Cristo sobre todas as conquistas, recebendo seu grão-prior a jurisdição ordinária episcopal, como prelado nulius 
diocesis, sobre as terras descobertas e por descobrir. À Ordem de Cristo cabia, portanto, o padroado dos benefícios infra episcopais das terras ultramarinas, enquanto os episcopais permaneciam, como no reino, pertencendo à Coroa. (LIMA, 2014. p. 47).

Conforme ensina Wander (2020) com a chegada da família real, o cenário religioso do período colonial, marcado pela dominação dos povos indígenas, por uma evangelização corrompida e pela relação entre Igreja-Estado nos moldes do Padroado, passou a ter novo capítulo. A família real chegava para se esconder das invasões napoleônicas estabelecendo no Rio de Janeiro sua base administrativa, transformando a vida política do Brasil, tornando-o, agora, em Reino Unido, e alterando suas relações com os ingleses protestantes.

Tal fato levou a família real a considerar permitir uma abertura para que as outras religiões, principalmente as protestantes, pudessem praticar sua fé. Ainda que de modo reservado e totalmente privado, tratava-se de uma forma de permitir o alcance de outros povos que possuíam relações internacionais com o Brasil e, com isso, despejavam aqui suas culturas e modos de fé. Nesse processo de abertura do monopólio da Igreja Católica sobre o Estado brasileiro é possível observar os diversos movimentos normativos que estruturaram a construção de um Brasil que viria a ser chamado de "livre", já que, agora, independe de sua colonizadora.

Assim, após a dissolução da Assembleia Constituinte por Dom Pedro I, com apoio dos militares, e imposta de cima para baixo, conforme Fausto (2006), para um povo entendido como uma minoria branca e mestiça, e que exercia cidadania pelo voto, houve a elaboração da primeira Constituição do Brasil. Separa-se o Brasil colônia de sua colonizadora, mas não se separa o Brasil da religião que o colonizou. Mantém-se assim, a Igreja Católica Apostólica Romana como a igreja oficial do Império.

Em 1824, no Brasil a Igreja Católica é declarada a religião oficial do Império, permitindo, contudo, o culto doméstico de outras religiões desde que esse seja realizado de modo estritamente privado, dentro das casas. Nesses vários movimentos que levariam à "laicidade formal", o Brasil consagra a liberdade religiosa como um direito básico do cidadão. Tal preceito, o da liberdade religiosa, como pondera Gabatz (2018), é fruto da análise que existia, naquele tempo, acerca da tolerância e essa pressupunha que o Estado somente poderia intervir com sua forca política no funcionamento dos cultos quando esses se revelassem atentatórios ao direito das pessoas ou das sociedades. Para Rui Barbosa (GABATZ, 2018), a 
liberdade religiosa seria uma complexidade de vertentes de ordem subjetivas ou objetivas, individuais ou coletivas, com dimensões positivas ou negativas.

Observa-se que o pluralismo religioso no Brasil, fez parte de uma grande competição religiosa que conforme Mariano (2011), ascende nos anos de 1950, com o crescimento acelerado dos movimentos pentecostais e a utilização dos diversos meios de mídia, como o rádio e a televisão, que passaram a dar visibilidade às ideologias de cada religião. Tal período foi marcado, também, pelo ingresso dos pentecostais na política partidária. Movimentos foram servindo para trazer uma releitura do tradicionalismo católico. Essa diversidade de opções de culto pela qual o povo ficou submetido devido à pluralidade de religiões, serviu para que fosse questionado todo o sentido daquele tradicionalismo católico gerando uma diversidade de opções para a vida religiosa das pessoas.

Foi em 1960, por reflexo da teologia da libertação e dos direitos humanos, que, conforme Mariano (2011) os processos internos da Igreja Católica passaram a reconhecer o direito à liberdade religiosa. É nesse período que a Igreja Católica faz uma opção pelo pobre, migrando de apoiadora para ser crítica do regime político adotado pelo Brasil naquela década. Essas mudanças de entendimento da Igreja Católica fizeram com que ela encontrasse legitimidade diante da população, uma vez que, vendo a opressão militar sobre o Estado Brasileiro, optou por deixar de apoiá-lo.

Após o período de 1964, que culminou com a constituição de 1988, o Brasil redesenha suas bases democráticas e, com isso, a participação da religião na esfera pública. A Constituição de 1988, conforme as anteriores, mantém em seu preâmbulo, expressamente o nome "Deus", deixando critérios abertos para a participação da religião no espaço público. O que se observou da nova carta política foi a manutenção do espírito que buscava afastar a relação Estado x religião oficial, ficando com o Estado uma função de garantidor de tolerância, quanto ao exercício da liberdade religiosa.

De fato, a religião fomenta reflexões de várias perspectivas, delineia uma dimensão existencial importante, gera um sentimento de pertencimento e de reconhecimento daquilo que nós somos e exprime uma identidade e um lugar para muitos na comunidade. No caso brasileiro, a religião revela uma espiritualidade pluralizada, expressa de formas variadas, até mesmo dentro de uma mesma religião, e retoma aspectos identitárias que a história não conseguiu apagar.

A religião, também, por outro lado, ao mesmo tempo em que provoca um lugar comum, também de certa forma exclui aqueles que não compartilham de sua mesma visão de 
mundo e dos valores que a constituem e, à medida em que seus adeptos levam para o debate político esse tipo de argumentação - com verdades prontas e arraigadas nos valores próprios fechados e sem permitir contrapontos -, qualquer tipo de consenso torna-se impossibilitado, pois, dessa forma, o discurso visa silenciar o outro. Esse é um equívoco cada vez mais frequente nos discursos religiosos.

A eclosão de crenças e ritos em formatos fundamentalistas, num quadro de intolerância e desrespeito com as liberdades individuais intenso, indicam que posturas de mais empatia e abertura para o diálogo precisam ser aprendidas juntamente com a compreensão de que uma democracia é o governo da maioria para a garantia do direito de todos. Assim, as minorias não podem ser desprezadas.

\section{A Teologia Pública frente a Laicidade Brasileira}

$A b$ initio, não se tem a pretensão de definir um conceito estático ou paradigmático sobre o que poderia ser chamado de Teologia Pública. Isso ocorre porque, em que pese os diversos movimentos que pretendem fomentar o diálogo e formular conceitos sobre o que seria a teologia pública, a limitação, ou melhor, a formatação de um conceito estático não parece possível. Qualquer tentativa de conceituação poderia deixar de considerar diversos fatores que fazem da teologia pública algo contextual. Além disso, outros fatores podem ser considerados. Conforme atesta Schimtt (SINNER, 2019) o Estado moderno é, em seus pontos incisivos, formado por conceitos teológicos secularizados, evidenciando que a religião na esfera pública sempre se faz presente, até mesmo em movimentos sinérgicos.

Kooman (2010) informa que o termo "Teologia Pública" foi utilizado pela primeira vez por Martin Marty, teólogo norte-americano 5 . Para analisar o termo "Teologia Pública”, Kooman pontua três sinais indicados por Stackhouse (apud KOOMAN, 2010). O primeiro ponto é o modo dogmático, o segundo é o modo polêmico e o terceiro, o modo apologético. Para os dogmáticos, contrários à Teologia Pública, a teologia tem a tarefa de articulação da fé, de clarificação do dogma. O modo polêmico enfrenta falsos ensinamentos e, por fim, o modo apologético tem por objetivo a busca de uma fé racional e acessível, levando em consideração a filosofia, teorias políticas, dentre outros.

\footnotetext{
${ }^{5}$ Segundo Kooman (2010), embora sem a utilização expressa do termo Teologia Pública, o mesmo já era praticado em outros momentos.
} 
A relação entre a Escola de Chicago e a de Yale é destacada por Kooman (2010), ao mostrar que a Escola de Chicago, de David Tracy, apresenta a dificuldade de uma universalização de assuntos públicos em contextos plurais e que para a Escola de Yale, a teologia pública deve viver de modo sincero e fiel as suas convicções de fé. O autor citado, possivelmente esperando certa neutralidade da Teologia Pública, destaca que a "teologia pública deve ser diferenciada das teologias da libertação, política, negra, feminista, africana e de outras teologias particularistas". (KOOMAN, 2010. p. 41).

Se o termo de Martin Marty, Kooman, Tracy, dentre outros, é importado, como seria possível buscar uma conceituação sobre o que seria Teologia Pública em território brasileiro?

Zefferino (2020), considerando o termo "Teologia Pública” e sua percepção no território brasileiro, em um mapeamento de textos sobre o tema, apresenta, como dinâmica, que o termo "Teologia Pública" pode apresentar as seguintes relações: (i) religião/teologia e espaço público; (ii) a dimensão pública da fé; (iii) como campo de pesquisa, no debate acadêmico e, por fim, na (iv) discussão sobre um discurso público da teologia. A multiplicidade de temas arrastados pela Teologia Pública ${ }^{6}$ brasileira mostra evidente a pluralidade de possibilidades que a mesma propõe.

Zabatiero (2013), por exemplo, articula dois pensamentos sobre teologia pública. Um primeiro pensamento é fundamentado em artigo escrito por Dirk Smit, e o segundo em artigo desenvolvido por Andries Van Aarde. Dos modelos de teologia pública apresentados, em Smit vê-se a importância de uma discussão sociológica do tema e, em Van Aarde, por sua vez, o que se tem é a necessidade de a teologia pública sair da esfera de teólogos e pastores e passar às mãos de diretores de cinema e artistas, por exemplo. Criticada por ser abrangente, a ideia de Andries Van Aarde retira do ambiente dos acadêmicos e pastores a possibilidade de realizar no ambiente público seus pensamentos e manifestações. Como forma de responder o que seria a Teologia Pública, Zabatiero (2013) apresenta-a como uma voz no modo de constituir o espaço público.

\footnotetext{
${ }^{6}$ No senso comum, não se torna difícil atrelar a ideia de Teologia Pública como uma atuação política da religião ou como uma atuação puramente acadêmica, sendo assim, limitados os atores que nela agem, como, por exemplo, políticos ou professores.
} 
A formatação de um espaço público que tem a Teologia Pública como sendo uma voz soa interessante uma vez que leva a ideia de que a Teologia Pública pode ser ruído, clamor, queixa, mas também pode ser, conselho, apelo e orientação. E mais, ser voz significa que a Teologia Pública verbaliza uma ideia que, como se verá mais para frente, é resultado da relação entre a fé e os mais diversos contextos.

Agora, se de um lado a teologia pública é voz que se faz no espaço público, sendo multifacetária, de outro lado não se pode, contudo, confundir o direito de voz no espaço público com direito de dominá-lo, de nele impor ideias e convicções.

No inspirador texto produzido por Menezes (2020), Diálogo sobre o Deus desconhecido: Paulo, Halík e eu no areópago, observa-se que Paulo ocupa a Praça em Atenas e esse ocupar, contudo, não significa um esbulho dos que ali estavam com o intuito de tomar para si, ou dominar, a Praça Ateniense. Paulo ocupa a praça como um lugar de encontro. Ora, se o espaço público é um lugar de muitas vozes, mais do que vozes que discursam ou debatem, são vozes que se encontram. Como lugar de encontro, são vozes que partem de lugares diferentes, mas se aproximam, se apresentam, se conhecem, se tensionam e se resolvem. São vozes que partem, cada qual, levando o que de cada qual é.

$\mathrm{Na}$ ideia de que cada voz leva para o espaço público o que tem, interessante a perspectiva de Gonçalves (2012, p. 26) que conceitua Teologia Pública como sendo “discurso que se constrói a partir da fé em Deus e estabelece uma relação com o contexto em que determinada comunidade cristã ou pensamento teológico se encontra". Essa relação entre "fé" e "contexto" é o que faz com que a Teologia Pública seja dialogal, ou seja, uma voz que fala "para fora", que leva algo.

A Teologia Pública, então, mais do que uma proposta de conceito que a universalize ou a delimite, precisa de um modo de efetivá-la como um instrumento que permita, em um ambiente plural, um lugar de encontro. Logo, mais que teoria, a Teologia Pública precisa ser uma prática que parte de um múltiplo fazer em um espaço cujo monopólio não está dado a ninguém, senão a todos.

Agora, sendo essa uma pequena aproximação do que viria a ser Teologia Pública, um lugar de encontro de várias vozes, qual seria o seu papel em Estado laico? Seria possível uma função dialogal transformada em práxis?

Roque Junges, em entrevista concedida ao IHU On-Line da Unisinos, sobre a especificidade da Teologia Pública e o que ela traria de novo para o Cristianismo, afirma que a Teologia Pública seria a presença da fé cristã dentro da universidade e serviria como forma de 
ajudar a repensar o papel do cristianismo na sociedade atual com um aprofundamento da identidade cristã. A Teologia Pública como uma reflexão, nessa ideia de Roque, somado à noção de aprofundamento da identidade, mostra que ela seria não só dialogal, mas uma práxis que dialoga de modo singular no ambiente público. Conforme Tracy (2006, apud FLORES) a Teologia Pública tem como público a sociedade, a academia e a Igreja e nesses ambientes, expõe e propõe respostas a questões fundamentais do homem:

A teologia é uma disciplina do pensamento que responde a questões humanas fundamentais, e é essencial para aqueles que estão na sociedade saber como devemos viver, que tipo de sociedade devemos formar, o que entendemos por justiça, autono/mia ou liberdade. A teologia responde a esse tipo de perguntas, e as pessoas que fazem parte da sociedade e que levam a teologia a sério têm o direito de propor as suas perguntas e respostas, e se engajar em discussões públicas sobre elas. (FLORES, 2019).

Observa-se então, que "o fazer Teologia Pública” parte de uma multiplicidade de ambientes e nesses ambientes, não parte de um mero discurso, mas sim, de um diálogo que deve ser feito entre as diversas formas de conhecimento, buscando entre elas uma aproximação, ou seja, é um diálogo que precisa ir "além da confissão" e ser uma "maneira de falar de Deus e sua vontade (Reino de Deus) que seja condizente e intelectualmente possível no emaranhado de ideias, conceitos e comportamentos da atual conjuntura global”. (GONÇALVES, 2012. p. 28). Seria, então uma teologia que se faria para fora. Aqui, em uma teologia que se faz para fora, acredito que seria possível acrescentar: uma Teologia Profética. Seria uma Teologia que anuncia e denuncia. Essa relação de anunciar e denunciar, pode ser aplicada ao "modelo" de práxis de Teologia Pública apresentado por Rosa (2020), em que a Teologia Pública deve ser intencional e pedagógica, sendo que o amor motiva viver a fé na vida comunitária, na vida real.

O que seria essa "vida real"? Parece que essa pergunta pretende distinguir uma vida imaginária, uma vida de percepções não concretas, para uma vida de sentido, de autenticidade ${ }^{7}$. Logo, a Teologia Pública deve ser, em tudo, autêntica.

Em entrevista à IHU On-Line, da Unisinos, Vattimo, falando sobre o pensamento de Heidegger, afirmou que "autenticidade significa co-responder à chamada do ser; mas o ser assim entendido é também a própria comunidade, a sociedade na qual se vive, etc.” Parece que

\footnotetext{
${ }^{7}$ Podemos dizer: uma vida desiludida, sem qualquer ilusão, caso fosse possível.

REVISTA RELEGENS THRÉSKEIA - 2021 - UFPR
} 
é isso: a vida real é a vida autêntica ${ }^{8}$, que leva em consideração o ser e sua identidade em razão de sua sociedade e comunidade?

A Teologia Pública, diante da laicidade estatal, não confronta o Estado, não o ofende, nem com ele é incompatível. Ela é voz, voz que se encontra com as outras vozes no espaço público. É voz autêntica que não pretende ocupar espaço outro que não o seu. Não busca uma pauta ou uma ideologia, mas acima de tudo possibilita o diálogo na construção do bem comum.

\section{Considerações finais}

A pesquisa realizada neste artigo teve como objetivo contribuir com o intenso debate que se dá em torno da presença religiosa e da teologia no espaço público brasileiro, trazendo como referências as relações existentes entre a laicidade, a multiplicidade de vozes e ideias crescentes no espaço público brasileiro e o lugar da Teologia nesse contexto multifacetado.

Nessa perspectiva, observamos que Teologia Pública não pode ser circunscrita a um conceito estanque, ao contrário, deve ser percebida como aquela que, por meio do diálogo e de um fazer centrífugo, pretende ser uma voz, dentre tantas outras. É voz e ação que se encontram no espaço público com várias outras vozes e, com elas, para além da confessionalidade, constroem a vida real, mesmo que seja cada qual com o seu real, mas, em diálogos autênticos.

Assim, a Teologia Pública no Brasil não pode ser outra senão aquela que observa a realidade do contexto da comunidade brasileira; que se faz com os pés no chão do Brasil; do crucifixo pendurado nas salas dos órgãos públicos; do Cristo de braços abertos no Corcovado; da peregrinação para Aparecida do Norte; que mantém Deus no Preâmbulo da Constituição Federal; que ainda abre as escolas para o ensino confessional; que tem o Jesus da estação primeira de Nazaré; do rosto negro, de sangue de índio e de corpo de mulher. É aqui onde o ser (da Teologia Pública) se faz real e possibilita o diálogo para a construção de uma laicidade que inclui a fé no debate, como uma voz que não se sobreponha às diversas outras vozes que devem compor uma sociedade pautada pela liberdade religiosa e pela democracia.

\footnotetext{
${ }^{8}$ A autenticidade, o compromisso com a verdade e essência do ser, deve fazer com que a Teologia Pública dê sua contribuição ao espaço público por meio de "sua voz". Logo, é voz própria. É saber que a teologia tem respostas, e as quer dizer.

${ }^{9}$ Interessante a observação de Rousseau (s.d.) em que a vida social, a partir da família natural em que as relações com o tempo se rompem, é uma mera convenção. Logo, lugar de liberdade de encontro.

REVISTARELEGENS THRÉSKEIA - 2021 - UFPR
} 


\section{REFERÊNCIAS}

AQUINO, S. T. (s.d.). Suma Teológica. Disponível em: https://sumateologica.files.wordpress.com/2017/04/suma-teolc3b3gica.pdf. Acesso em: $11 / 08 / 2021$.

ARISTÓTELES. A Política. São Paulo: EDIPEDRO. Disponível em: http://www.dhnet.org.br/direitos/anthist/marcos/hdh_aristoteles_a_politica.pdf. Acesso em: 11/08/2021.

CAMURÇA, M. A. A questão da laicidade no Brasil: mosaico de configurações e arena de controvérsias. HORIZONTE - Revista de Estudos de Teologia e Ciências da Religião, v. 15, n. 47, p. 855-886, 30 set. 2017.

FAUSTO. B. História do Brasil. Ed. Usp. 12ª Edição. 2006.

FLORES, N. M. Qual é o papel de um Teólogo Público hoje? Revista IHU On-Line. Disponível em: http://www.ihu.unisinos.br/78-noticias/590862-qual-e-o-papel-de-um-teologo-publicohoje. Acesso em: 11/08/2021.

GABATZ. C. O Estado Laico e a Liberdade Religiosa no Brasil: o Acordo Brasil - Santa Sé e a "Lei Geral das Religiões". Direitos Culturais. Santo Ângelo, v. 13, n. 29, p. 47-66 jan/abr. 2018.

GONÇALVES, A. Pastoral Pública: a possibilidade de uma práxis a partir da Teologia Pública. Protestantismo em Revista. Disponível em: http://periodicos.est.edu.br/index.php/nepp/article/view/297. Acesso em: 11/08/2021.

GONÇALVES, M. Intefrismo Católico e Fundamentalismo Protestante Comparados: Historicidade, Aproximação e Distanciamento. Revista Relegens Thréskeia. Disponível em: https://revistas.ufpr.br/relegens/article/view/31086. Acesso em: 11/08/2021.

HABERMAS, J. Fé e Saber. São Paulo: Editoraa Unesp, 2015.

JUNGES, J. R. O que a Teologia pública traz de novo. Cadernos IHU em Formação (UNISINOS), São Leopoldo, v. 2, n.8, p. 5-8, 2006.

KOOPMAN, Nico. Apontamentos sobre a Teologia Pública hoje. Protestantismo em Revista. Disponível em: www.est.edu.br/periodicos/index.php/nepp/article/download/29/67. Acesso em: 11/08/2021.

LIMA. L. L. G. O Padroado e a Sustentação do Clero no Brasil Colonial. Seculum. Revista de História. João Pessoa. jan./jun. 2014.

MARIANO. R. Laicidade à Brasileira. Católicos, pentecostais e laicos em disputa na esfera pública. Disponível em: https://www2.ufjf.br/ppcir//files/2013/10/texto-1.pdf. Acesso em: $11 / 08 / 2021$. 
MONTERO, P. Secularização e espaço público: a reinvenção do pluralismo religioso no Brasil. Etnográfica. Disponível em: http://journals.openedition.org/etnografica/1195. Acesso em: 11/08/2021.

PROENÇA. W. L. História do Cristianismo III. Faculdade Teológica Sul Americana, 2020. ROUSSEAU, K.-J. (s.d.). Do Contrato Social. Edição Eletrônica: Ridendo Castigat Mores. Disponível em: http://www.dhnet.org.br/direitos/anthist/marcos/hdh_rousseau_contrato_social.pdf. Acesso em: 11/08/2021.

VON SINNER, R. Teologia Pública num Estado Laico. Ensaios e análises. Coleção Teologia Pública 7. São Leopoldo: Sinodal, 2018.

VATTIMO, G. O nazismo e o "erro" filosófico de Heidegger. Revista IHU On-Line. Disponível em: http://www.ihuonline.unisinos.br/media/pdf/IHUOnlineEdicao187.pdf. Acesso em: 11/08/2021

ZEFERINO, J. A Teologia Pública no Brasil. Interações, v. 15, n. 1, p. 90-107, 6 fev. 2020. ORO, A. P. Religião e política no Brasil. Cahiers des Amériques latines. Disponível em: https://www.researchgate.net/publication/320325006_Religiao_e_politica_no_Brasil. Acesso em: 11/08/2021. 